\title{
Buspirone Ameliorates the Morphine Withdrawal-Induced Anxiety through Synaptic Ultrastructural Changes in Hippocampus of Rat
}

\author{
Jialin Gao ${ }^{1,2 \#}$, Gang Qian ${ }^{1 \#}$, Suyuan Luo ${ }^{1 \dagger}$, Yan Tian ${ }^{1}$, Mingsong Wu ${ }^{1}$, Zhongxiang Yao ${ }^{3 \dagger}$ \\ ${ }^{1}$ Department of Cell Biology and Genetics, Zunyi Medical College, Zunyi, China \\ ${ }^{2}$ Department of Endocrinology and Genetic Metabolism, Yijishan Hospital of \\ Wannan Medical College, Wuhu, China \\ ${ }^{3}$ Department of Physiology, The Third Military Medical University, Chongqing, China \\ Email: 'swx_100@163.com, †yaozhx@yahoo.com
}

Received August 15 $5^{\text {th }}, 2013$; revised September 12 $2^{\text {th }}, 2013$; accepted September $29^{\text {th }}, 2013$

Copyright (C) 2013 Jialin Gao et al. This is an open access article distributed under the Creative Commons Attribution License, which permits unrestricted use, distribution, and reproduction in any medium, provided the original work is properly cited.

\begin{abstract}
Morphine administration causes long-lasting neural changes in the brain that underpin the behavioral abnormalities, and the relationship between structural changes and behavioral symptoms is obscure. In present study, the elevated plus-maze and transmission electron microscope were applied to validate the anxiety-like behaviors and synaptic ultrastructural changes in the hippocampi of rats among the morphine group (morphine administration only), the buspirone group (morphine plus buspirone administration) and the vehicle (saline treated only). As compared with the vehicle group, lower values of OE (times of entering into the open arms), OE\% (percentage of entries into the open arms), OT (time spent in the open arms), OT\% (percentage of time stayed in the open arms), Ns (surface density (Sv)/numerical density $(\mathrm{Nv})$ ) and $\mathrm{S}$ (surface area) of synapses were observed in the morphine group , but significantly, behavior higher scores of RR (rearing), HD (head-dipping), FBA (flat back approach), and higher $N v, S v$, PSD (postsynaptic density), LPT (length of postsynaptic thickening), WCJ (widths in synaptic cleft on junctions) and CCR (curvature of the cleft region) of synapses appeared in the morphine group. However, no significant differences in values of most of those parameters above were detected between the vehicle group and the buspirone group. These results supported that anxiety-like symptoms of rats significantly occurred to the rats after acute morphine withdrawal, but buspirone administration could reverse these indexes. It also proved that the appearance/disappearance of anxiety-related symptoms was related to the ultrastructural changes/reversibility of synapses in the hippocampus with morphine and buspirone administrations. So, it suggested that anxiety-related symptoms were modified in rats subjected to the synaptic ultrastructural changes in hippocampus by morphine acute withdrawal and were further rehabilitated by buspirone administration. It is helpful to pursue the effective therapeutic methods of morphine addiction.
\end{abstract}

Keywords: Buspirone; Morphine; Anxiety; Synaptic Ultrastructure; Hippocampus

\section{Introduction}

Chronic morphine administration can induce the changes of hippocampal CA1 neurocircuitry which modulate the synaptic plasticity through the regulation of long-term potentiation (LTP) and long-term depression (LTD) (Salmanzadeh et al., 2003). The synaptic plasticity is widely studied in hippocampal CA1 and CA3 fields, which is believed to be the mechanism underlying certain types of learning and memory (Moron et al., 2007). It is a commonly accepted assumption that an increase in neuropil volume reflects an increase in the number of synapses present (Devoogd et al., 1985; Turner \& Greenough, 1985; Black et al., 1990; Withers et al., 1993; Klintsova et al., 2000), but, in many regions of the brain, this has not yet to be clearly estab-

\footnotetext{
*The authors had no conflicts of interest to declare in relation to this article.

\#The first two authors have contributed equally to this paper.

${ }^{\dagger}$ Corresponding author.
}

lished (Brown et al., 2002).

Buspirone, a potent anxiolytic compound in animal models (Riblet, et al., 1986), displays reversibility of synaptic activation of pyramidal cells in the hippocampus (Trulson et al.,1986; Mauk et al., 1988). It showed that buspirone bind selectively to presynaptic (dorsal raphe) and postsynaptic (hippocampus, cortex) 5-hydroxytryptamine $1 \mathrm{~A}(5-\mathrm{HT} 1 \mathrm{~A})$ receptor binding sites, and the clinical trials of anxiety and depression may be related to the buspirone's interactions with gepirone at pre-synaptic and postsynaptic 5-HT1A receptor (Yocca, 1990). Buspirone had no effect on the immediate rewarding properties of cocaine, but the attenuation of 5-HT neurotransmission (via the autoreceptor agonist properties of buspirone) could reverse the negative impact of cocaine (Ettenberg \& Bernardi, 2007).

So, the correlating ethological indexes of anxious rats with synaptic ultrastructural changes of the hippocampal CA1 and CA3 fields should enable us to evaluate the mechanism of 
morphine addiction and pursue the effective therapeutic methods. We hypothesized that anxiety-related symptoms were modified in rats subjected to the synaptic ultrastructural changes in hippocampal CA1 and CA3 fields by morphine acute withdrawal and were further rehabilitated by buspirone administration. Here, we should provide an evidence in which the appearance/disappearance of anxiety-related symptoms are related to the synaptic ultrastructural change/reversibility of the hippocampal CA1 and CA3 fields with morphine and buspirone administrations.

\section{Method}

\section{Animals}

Adult male Sprague Dawley rats (weighing 200 - 250 g) were obtained from the Laboratory Animal Center, the Third Military Medical University (Chongqing, China). Supplied with water and food available ad libitum, rats were maintained in groups on a 12-h light/dark cycle (lights on at 08:00 AM) and were allowed to acclimatize to their environment for 1 week prior to drug administration. All treatments were strictly in accordance with National Institutes of Health Guide for the Care and Use of Laboratory Animals.

\section{Morphine and Buspirone Administration for the Elevated Plus-Maze Tests}

Rats were randomly assigned to three groups ( $n=12$ each group): the saline treated control group (saline group), the morphine treated model group (morphine group) and the morphine plus buspirone treated experimental group (buspirone group). Morphine (morphine sulfate) was prepared in $0.9 \%$ sterile isotonic saline. In morphine group and buspirone group, three escalating doses of morphine $(5,10$, and $15 \mathrm{mg} / \mathrm{kg}$, s.c., twice per day at $12 \mathrm{hr}$ intervals) were applied for 10-day injecttions as described before (Morinville et al., 2003). Briefly, a dosage of $5 \mathrm{mg} / \mathrm{kg}$ morphine was applied at the primal period of 5 days, followed by 3-day injections of $10 \mathrm{mg} / \mathrm{kg}$, then of 15 $\mathrm{mg} / \mathrm{kg}$ in the last two days. Withdrawal syndrome was precipitated with abrupt termination of morphine intake by replacement of daily injections of saline for 3 days, and was further validated by observing behaviors in a separate series of experiments. After acute morphine withdrawal, each anxious rat in the buspirone group received buspirone treatment $(15 \mathrm{mg} / \mathrm{kg}$, i.g., twice per day at $12 \mathrm{hr}$ intervals) for 3 days while the anxious rats in the morphine group only received saline treatment by the same form. The rats of saline group only received saline as the program above.

All rats were tested just once after $72 \mathrm{~h}$ of the last treatments of saline or buspirone. To begin a test session, rats were individually placed in the center of the maze, facing towards one of the enclosed arms, and allowed $5 \mathrm{~min}$ of free exploration. The elevated plus-maze apparatus consisted of a center $(10 \times 10 \mathrm{~cm}$ square area), two opposing open arms $(50 \mathrm{~cm}$ length, $10 \mathrm{~cm}$ width and $40 \mathrm{~cm}$ height), and two opposing closed arms $(50 \mathrm{~cm}$ length, $10 \mathrm{~cm}$ width and $40 \mathrm{~cm}$ height). Each of the four arms in the maze was connected to the center at $90^{\circ}$ relative to the adjacent arms. All sides and floor surfaces of the open and closed arms were constructed from black Plexiglas. The floor of the maze was covered with a thin layer of vulcanized black rubber to facilitate inter-trail cleaning. All trials took place in a dimly illuminated chamber and were recorded by a video cam- era that was linked to a video monitor, and an IBM-compatible computer positioned outside the test chamber. Behaviors of the rats were recorded with an automated system. Positions of the rats in the maze were continuously tracked by photo beam arrays embedded along the entire length of the base of each closed arm, the entry point to all arms, and in clear Plexiglas tubes that extended from the distal end of each closed arm and ran parallel to the open arms.

An auto-recorded system was applied to collect data and further these behavior measurements were analyzed using Motor Monitor Software (Kinder Scientific, Poway CA). Based on computer-recorded data, judgment of anxiety-like behaviors were validated by the following parameters for each rat: (1) times of rat entering into the open arms (OE); (2) the percentage of entries into the open arms as the total entries into both open and closed arms (OE\%); (3) time spent in the open arms (OT); (4) the percentage of time stayed in the open arms as in both open and closed arms (OT\%); (5) partial or total rising onto hind limbs (rearing, RR); (6) exploratory movement of head/shoulders over the sides of the maze and down toward the floor (Head-dipping, HD); and (7) locomotion when the animal stretched to its full length and cautiously moves forward (Flat-back approach, FBA).

\section{Tissue Processing for Electron Microscopy}

Hippocampal samples were harvested from rats of three separate groups ( $n=6$ per group). The animals were decapitated after $72 \mathrm{~h}$ of the last injections of saline or buspirone. According to standard procedures (Harris \& Sultan, 1995; Shepherd \& Harris, 1998), the brains were removed, and slices of the hippocampi were rapidly dissected free. Brains were sectioned coronally at $200 \mu \mathrm{m}$ on a vibratome; the CA1 and CA3 fields were blocked from sections containing the dorsal hippocampus (bregma -2.3 to $-4.3 \mathrm{~mm}$, mediolateral $0-2 \mathrm{~mm}$ ) with a tissue chopper into ice-cold phosphate buffered solution containing (in mM) $117 \mathrm{NaCl}, 4.7 \mathrm{KCl}, 26 \mathrm{NaHCO}_{3}, 1 \mathrm{NaH}_{2} \mathrm{PO}_{4}$, $2.2 \mathrm{CaCl}_{2}, 1.2 \mathrm{MgSO}_{4}$, and 10 glucose, $\mathrm{pH}$ 7.4. The slices were fixed rapidly in $6 \%$ glutaraldehyde and $4 \%$ paraformaldehyde in $100 \mathrm{mM}$ cacodylate buffer for $8 \mathrm{sec}$ under microwave irradiation (Jensen \& Harris, 1989), stored overnight in the fixative, and then rinsed in buffer. Slices were bathed with $1 \%$ osmium and $1.5 \%$ potassium ferrocyanide in $100 \mathrm{mM}$ cacodylate buffer, cooled in ice bath to $12^{\circ} \mathrm{C}$, and microwave for $2 \mathrm{~min}$ at $37^{\circ} \mathrm{C}$. After several buffer rinses, they were en bloc stained using $2 \%$ aqueous uranyl acetate while being cooled on ice and were microwave $2 \mathrm{~min}$ at room temperature. Samples were dehydrated in an acetone series $(50 \%, 70 \%, 90 \%$, and $100 \%)$ for 40 sec each in the microwave at $37^{\circ} \mathrm{C}$. The following treatments, involved in infiltration and embedded coffin mold, were performed as described before (Shepherd \& Harris, 1998). These sections were embedded in Agar 100 resin and polymerized for $48 \mathrm{hr}$ at $60^{\circ} \mathrm{C}$. The block face was trimmed to include one entire antennat lobe in the ultrathin, and then a subset of six 70 $\mathrm{nm}$-thin sections were selected in a random systematic manner from the entire section set for analysis using TEM. Thin sections were mounted on Pioloform-coated slot grid and counterstained with saturated ethanolic uranyl acetate, followed by Reynolds lead citrate, each for $5 \mathrm{~min}$. The target areas, hippocampal CA1 and CA3 fields between strata pyramidale and lacunosum moleculare, were examined with a Hitachi H-600 transmission electron microscope. 


\section{Stereological Measurements of Synapses}

Serial electron micrographs (12 photographs per section, from left top to low right) were taken on a Hitachi H-600 transmission electron microscope operating at $80 \mathrm{kV}$. Images were collected onto $35 \mathrm{~mm}$ plate film at a final magnification of 44,000 $\times$ and enlarged onto $7 \times 12$ inch photographic paper. Within each photograph, the points used for analysis were determined by placing a $9 \mathrm{~mm}^{2}$ transparent grid over a micrograph. Stereological quantification of synapses was determined using the physical dissector method. The accurate and unbiased comparesons of numerical density $(N v)$, surface area $(S)$, surface density $(\mathrm{Sv})$ and the average surface density of each synapse $(\mathrm{Ns})$ in the hippocampal CA1 and CA3 fields were measured as described before (Sterio, 1984). These parameters such as the total synapse number per $\mu \mathrm{m}^{2}(\mathrm{Na})$, the mean synapses strip length $(L)$, the sample thickness $(T)$, the total grid length $(L t)$, and the cross point $(\mathrm{Ni})$ between grid and synapses were recorded. Accordingly, the emendation coefficient $(\mathrm{Ko})$ was calculated as follows: $K o=1+3 T / 2 L$. Based on these sufficient parameters, stereological analysis was respectively described as the following formulas: $N v=N a \cdot L^{-1}(K o+T), S v=2 N i / L t \cdot K o$, and $N s=S v / N v$.

\section{Further Measurements of Synaptic Junction Parameters}

All identifiable synaptic junctions were marked on the micrographs above and used for further measurement. Asymmetric synapses were identified, and postsynaptic elements were classified as dendritic spines or dendritic shafts, by established morphological criteria (Scheuermann, 1991). The criterion of parallelism was waived when terminals were sectioned at an oblique angle to the cleft specialization if the presence of a thickening and synaptic vesicles was still obvious. The numbers and the areas of the synaptic junctions were recorded in order to determine postsynaptic density (PSD).

According to description before (Weibel, 1966), the membranous boundaries of terminals were outlined and a curly probe was used to determine terminal areas by permitting point counts for area estimate. More detailed measurements of terminal parameters were undertaken as described before (Dyson \& Jones, 1980). A curvature-length probe (Jones \& Devon, 1978) was used to measure the length of postsynaptic thickening (LPT) and the width in synaptic cleft on junctions (WCJ) at the cleft edge of the thickening, and to determine junction curvature (curvature of the cleft region, CCR) at these positions. LPT was measured directly along the arc of curvature. Adjacent junctions on the same terminal separated by membrane free of specialization were set aside.

\section{Statistical Analysis}

All data obtained from behavioral measurements of plusmaze activity, stereological detections and synaptic terminal junction parameters were subjected to one-way analysis of variance (ANOVA) as dictated by the experimental design. The mean differences were compared by least significant difference test. All analyses were performed on a completely randomized design using the Minitab software package and a value of $p<$ 0.05 was considered to indicate statistical significance, $p<0.01$ very significant.

\section{Results}

\section{Anxiety-Like Behavioral Reactions}

As shown in Table 1, very significant withdrawal symptoms appeared in individuals of morphine group. One-way ANOVAS between morphine group and saline group subjects revealed notably significant carry-over effects of morphine administrition on $\mathrm{OT}, \mathrm{OE}, \mathrm{OT} \%, \mathrm{OE} \%, \mathrm{RR}, \mathrm{HD}$, and FBA parameters. As compared with the saline group, lower values of $\mathrm{OE}, \mathrm{OE} \%$, OT and OT $\%$ were observed in the morphine group $(p<0.01)$, but significantly, higher scores of RR, HD and FBA appeared in the morphine group $(p<0.01)$. However, no significant differences in values of these parameters above were detected between the saline group and the buspirone group $(p>0.05)$ except HD $(p<0.01)$. These results showed that a 10-day morphine treatment produced robust and anxiety-like behavioral response patterns in the elevated plus-maze, but the buspirone administration reversed them.

\section{Quantitatively Morphological Effects of Synapses}

As shown in Table 2 and Figure 1, it could be seen that significant differences occurred in hippocampal CA1 and CA3 fields in the morphine group, mainly in the profiles of presynapse and postsynapse membranes. As compared with the saline group, higher $N v$ and $S v$ (approximately 2 folds) were observed in the morphine group $(p<0.01$ or $p<0.05)$ in the hippocampal CA1 and CA3 fields; but significantly, lower values of $\mathrm{S}$ and $N s$ were detected in the hippocampal CA1 and CA3 fields $(p<0.01$ or $p<0.05)$. However, no significant differences in values of these parameters above were detected between the saline group and the buspirone group $(p>0.05)$ except $\mathrm{S}$ at CA1 $(p<0.01)$. These results showed that a 10 -day morphine administration changed the synaptic quantitatively morphological effects in hippocampal CA1 and CA3 fields, but the buspirone treatment reversed them.

Table 1.

Scores of ethological measures in three independent groups.

\begin{tabular}{cccccccc}
\hline & OT & OE & OT $\%$ & OE $\%$ & RR & FBA & \\
\hline Saline group & $68.11 \pm 2.08$ & $6.80 \pm 1.16$ & $0.25 \pm 0.04$ & $0.41 \pm 0.06$ & $1.40 \pm 0.66$ & $0.16 \pm 0.09$ \\
Morphine group & $44.03 \pm 3.04^{*}$ & $4.70 \pm 0.34^{*}$ & $0.11 \pm 0.07^{*}$ & $0.24 \pm 0.02^{*}$ & $6.82 \pm 1.07^{*}$ & $3.92 \pm 0.95^{*}$ & $33.56 \pm 1.28^{*}$ \\
Buspirone group & $65.01 \pm 7.02$ & $7.00 \pm 1.60$ & $0.25 \pm 0.06$ & $0.42 \pm 0.07$ & $1.55 \pm 0.81$ & $2.11 \pm 0.23^{\#}$ & $1.56 \pm 0.07$ \\
\hline
\end{tabular}

Values represent means \pm SEM $(n=12$ in each group). Significant differences: * from the respective saline group and buspirone group $(P<0.01)$. \# from the respective saline group and morphine group $(P<0.01)$. OT, time spent in the open arms; OE, times of entering into the open arms; OT\%, percentage of time stayed in the open arms; $\mathrm{OE} \%$, percentage of entries into the open arms; RR, rearing; HD, head-dipping; FBA, flat back approach. 
Table 2.

Quantitatively morphological effects of synapses in hippocampal CA1 and CA3 fields.

\begin{tabular}{|c|c|c|c|c|c|c|}
\hline & \multicolumn{3}{|c|}{ CA1 } & \multicolumn{3}{|c|}{$\mathrm{CA} 3$} \\
\hline & Saline group & Morphine group & Buspirone group & Saline group & Morphine group & Buspirone group \\
\hline $\mathrm{Nv}\left(\right.$ number $\left./ \mathrm{mm}^{3}\right)$ & $0.723 \pm 0.386$ & $1.513 \pm 0.817^{*} \Delta$ & $0.743 \pm 0.567$ & $0.667 \pm 0.282$ & $1.146 \pm 0.490^{*} \Delta$ & $0.801 \pm 0.361$ \\
\hline $\operatorname{Sv}\left(\mathrm{um}^{2} / \mathrm{um}^{3}\right)$ & $0.077 \pm 0.037$ & $0.103 \pm 0.052^{*} \Delta$ & $0.088 \pm 0.060$ & $0.044 \pm 0.018$ & $0.052 \pm 0.026 \#$ & $0.051 \pm 0.012$ \\
\hline $\mathrm{S}\left(\mathrm{um}^{2}\right)$ & $0.174 \pm 0.245$ & $0.079 \pm 0.046^{*} \boldsymbol{\Delta}$ & $0.348 \pm 0.179$ & $0.079 \pm 0.059$ & $0.059 \pm 0.055 \#$ & $0.062 \pm 0.041$ \\
\hline $\mathrm{Ns}(=\mathrm{Sv} / \mathrm{Nv})$ & 0.107 & 0.068 & 0.118 & 0.066 & 0.045 & 0.064 \\
\hline
\end{tabular}

Values represent means $\pm \operatorname{SEM}\left(n=6\right.$ in each group). Significant differences: ${ }^{*}$ from the respective saline group $(P<0.01)$; \# from the respective saline group $(P<0.05)$; $\Delta$ from the respective buspirone group $(P<0.01) ; \Delta$ from the respective buspirone group $(P<0.05)$. Nv, numerical density; Sv, surface density; $\mathrm{S}$, surface area; Ns, = $\mathrm{Sv} / \mathrm{Nv}$.

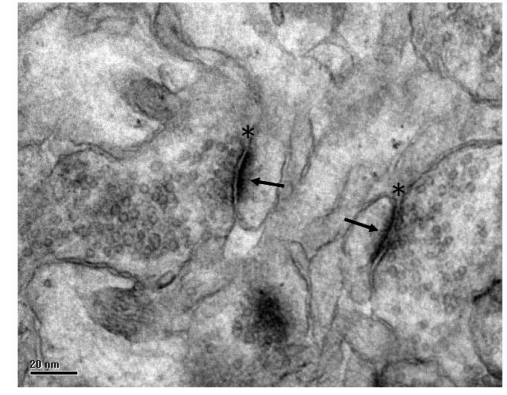

(a)

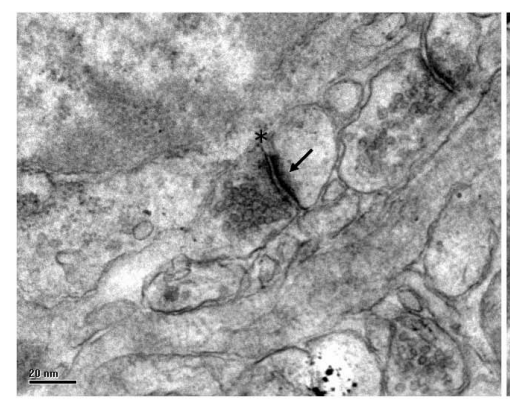

(d)

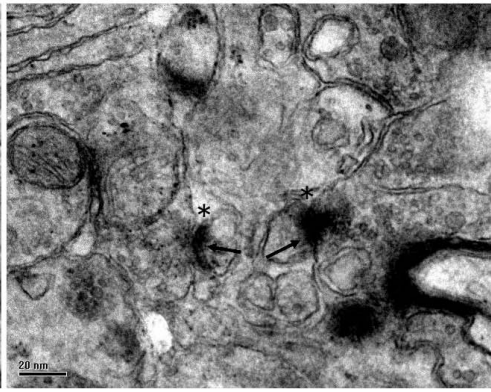

(b)

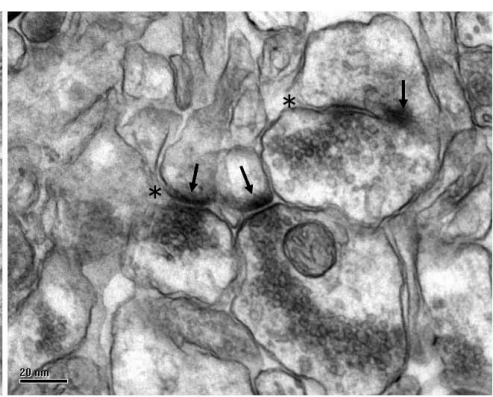

(e)

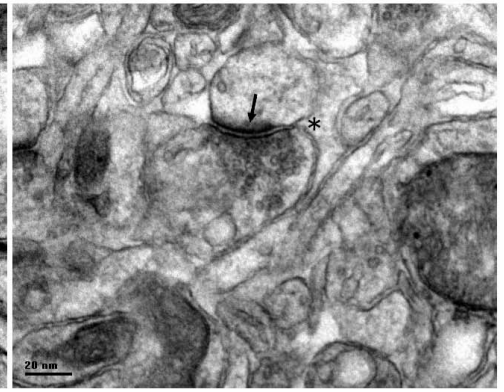

(c)

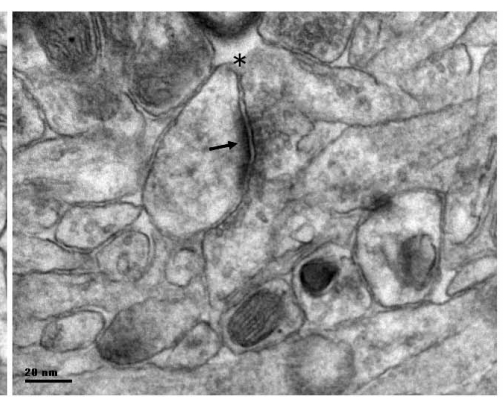

(f)

Figure 1.

Electron micrographs of the hippocampal CA1 and CA3 fields, showing the morphological differences of synapses in three independent groups $(\mathrm{n}=6$ in each group, $\mathrm{bar}=20 \mathrm{~nm})$. Thin synaptic profiles (arrows) and low values of PSD, LPT, WCJ, and CCR on the synaptic junctions (asterisk) at CA1 (A) and CA3 (D) fields in the saline group; Thick synaptic profiles (arrows) and high values of PSD, LPT, WCJ, and CCR on the synaptic junctions (asterisk) at CA1 (B) and CA3 (E) fields in the morphine group; Thin synaptic profiles (arrows) and low values of PSD, LPT, WCJ, and CCR on the synaptic junctions (asterisk) at CA1(C) and CA3 (F) fields in the buspirone group. PSD, postsynaptic density; LPT, length of postsynaptic thickening; WCJ, widths in synaptic cleft on junctions; CCR, curvature of the cleft region.

synaptic junction regions in any way reflect their functional states, more detailed measurements of terminal synaptic parameters were undertaken in the hippocampal CA1 and CA3 fields from three independent groups above (Table 3 and Figure 1). Significantly, higher values of PSD, LPT, WCJ and CCR from hippocampal CA1 and CA3 fields were observed in the morphine group than that in the saline group $(p<0.01$ or $p$ $<0.05$ ). To some extent, buspirone administration to the acute morphine withdrawal animals rehabilitated synaptic profile, the scores of most of these indexes above were only slightly increased in contrast with the saline group $(P>0.05)$, and they still were significant lower than that in the morphine group $(p<$ 0.01 or $p<0.05)$.

\section{Discussion}

Concerning the ethological measurements, anxiety related symptoms significantly occurred to the rats suffered from the escalating doses of morphine administration while they were exposed to the elevated plus-maze after $72 \mathrm{~h}$ acute morphine withdrawal, but buspirone administration can reverse these indexes. Morphine withdrawal increased ethological indexes related to exploration and locomotor behavior such as endexploration, head-dipping, rearing, and so on. These evidences indicated that morphine withdrawal increased the general motor activity and decreased aversion to the open spaces of the maze in rats. It has been reported that systemic injections of morphine 
Table 3.

Measurements of terminal synapse junctions in hippocampal CA1 and CA3 fields.

\begin{tabular}{|c|c|c|c|c|c|c|}
\hline & \multicolumn{3}{|c|}{ CA1 } & \multicolumn{3}{|c|}{$\mathrm{CA} 3$} \\
\hline & Saline group & Morphine group & Buspirone group & Saline group & Morphine group & Buspirone group \\
\hline PSD & $7.83 \pm 0.80$ & $10.86 \pm 0.86 \# \Delta$ & $8.37 \pm 1.58$ & $7.73 \pm 1.02$ & $12.86 \pm 1.15^{*} \Delta$ & $10.31 \pm 1.02$ \\
\hline LPT & $37.35 \pm 2.30$ & $44.93 \pm 3.48 * \Delta$ & $39.78 \pm 3.26$ & $45.66 \pm 3.81$ & $52.99 \pm 7.81 \# \boldsymbol{\Lambda}$ & $41.41 \pm 3.55$ \\
\hline WCJ & $2.34 \pm 0.29$ & $3.80 \pm 0.30 * \Delta$ & $3.07 \pm 0.22$ & $2.38 \pm 0.73$ & $3.81 \pm 0.59^{*} \Delta$ & $2.91 \pm 0.15$ \\
\hline $\mathrm{CCR}$ & $1.21 \pm 0.11$ & $1.37 \pm 0.12 * \Delta$ & $1.29 \pm 0.14$ & $1.23 \pm 0.18$ & $1.39 \pm 0.30^{*} \Delta$ & $1.30 \pm 0.14$ \\
\hline
\end{tabular}

Values represent means $\pm \operatorname{SEM}(n=6$ in each group). Significant differences: *from the respective saline group $(P<0.01)$; \# from the respective saline group $(P<0.05)$; $\Delta$ from the respective buspirone group $(P<0.01) ; \Delta$ from the respective buspirone group $(P<0.05)$. PSD, postsynaptic density; LPT, length of postsynaptic thickening; WCJ, widths in synaptic cleft on junctions; CCR, curvature of the cleft region.

may produce euphoric or dysphoric effects (Ebert et al., 1998). It was commenced establishment of anxiety symptoms in rats by opiate administration because of the similarities in time course and intensities of craving and anxiety experienced during acute opiate withdrawal (Swift \& Stout, 1992). The intraperitoneal injections of morphine $(0.1$ and $0.3 \mathrm{mg} / \mathrm{kg})$ in rats increased both the total entries into the arms and the percentage of entries and time spent in the open arms of the maze (Anseloni et al., 1999).

Opioid ligands may mediate reward or aversive process depending on the structures on which they are acting and on the receptor types with which they interact (Mucha \& Herz, 1985; Bals-Kubik et al., 1989). It is a commonly accepted assumption that an increase in neuropil volume reflects the increase in the number of synapses (Klintsova et al., 2000), but in many regions of brain, this has yet to be clearly established (Brown et al., 2002). It has been suggested that the increase in the motor activity caused by opiate may be due to the activation of dopaminergic cells in mesolimbic system (Koob, 1992). Indeed, morphine injections into the ventral tegmental area (VTA) can increase the dopamine-dependent locomotion (Yuan et al., 1992). Previous models of dysphoria-like and anxiety-like behaviors resulting from acute opioid dependence suggested the dopaminergic pathway may also play a prominent role in the transition from casual to compulsive use (Zhang \& Schulteis, 2008).

In the present study, both behavioral and synaptic data are consistent with the idea that synaptic potentiation on hippocampus is critical for the appearance in anxiety-like behavior. The collaterals of axons between cortex and the granule cells in hippocampal dentate gyrus (DG) innervate the distal parts of the apical dendrities of pyramidal neurons in hippocampal CA1 and CA3 fields (Safiulina et al., 2005). The striking differences in the structural changes of hippocampal CA1 and CA3 fields suggested that the anxiety-like symptoms may be related to morphological changes in rats, associated with morphine and buspirone administrations. It is a good confirmation with our results that anterograde and retrograde alteration related to synaptic plasticity are necessary for memory formation (Morris et al., 2003). It is also supporting our results that tianeptine administrition for several hours is able to reverse the effects of stress when the stress and anesthesia onset is remarkable (Shakesby et al., 2002). In an attempt to isolate the principal driving force(s) of structural plasticity from combined influences of age, behavior, and hormonal control, it is found that structural changes in the antennal lobes of the bee coincide not only with shifts in the tasks being performed but also with behavioral changes associated with olfactory learning and memory. Based on correlation between thickness of the postsynaptic nucleus density and excitatory or inhibitory function of a synapse holding in the nucleus, it argued that the changes in morphology of synapses contributed some inhibitory synapses to excitatory contacts (Guldner \& Ingham, 1980). Recent evidences demonstrated that synaptic plasticity in hippocampalnucleus accumbens (NAc) was disrupted by repeated cocaine treatment (Goto \& Grace, 2005). Taken together these data, we suggested that, related to functional roles of hippocampal CA1 and CA3 fields, the changes of these excitatory synapses on dopaminergic cells were a neural adaption common to all major classes of addictive substances and therefore might play a critical role in the development of addiction.

In conclusion, we showed that anxiety-like symptoms of rats significantly occurred to the rats after acute morphine withdrawal, but buspirone administration could reverse these indexes. We also proved that the appearance/disappearance of anxietyrelated symptoms was related to the ultrastructural changes/reversibility of synapses in the hippocampus with morphine and buspirone administrations. So, these results are theoretically related the psychological symptoms with neural circuitry regulation. Future studies will focus on the hippocampal neuron signal pathway of the buspirone administration after the morphine acute withdrawal. It is helpful to pursue the effective therapeutic methods of morphine addiction.

\section{Acknowledgements}

The authors greatly acknowledge the financial support of this project by the National Natural Science Foundation of China (No. 30860373), the Special Foundation for Development of Guizhou Province College in China (No. 2005109) and the Key Project of the Chinese Ministry of Education (No. 206136).

\section{REFERENCES}

Anseloni, V. C., Coimbra, N. C., Morato, S., \& Brandao, M. L. (1999). A comparative study of the effects of morphine in the dorsal periaqueductal gray and nucleus accumbens of rats submitted to the elevated plus-maze test. Experimental brain research Experimentelle Hirnforschung, 129, 260-268. http://dx.doi.org/10.1007/s002210050896

Bals-Kubik, R., Herz, A., \& Shippenberg, T. S. (1989). Evidence that the aversive effects of opioid antagonists and kappa-agonists are centrally mediated. Psychopharmacology, 98, 203-206. 
http://dx.doi.org/10.1007/BF00444692

Black, J. E., Isaacs, K. R., Anderson, B. J., Alcantara, A. A., \& Greenough, W. T. (1990). Learning causes synaptogenesis, whereas motor activity causes angiogenesis, in cerebellar cortex of adult rats. Proceedings of the National Academy of Sciences of the United States of America, 87, 5568-5572. http://dx.doi.org/10.1073/pnas.87.14.5568

Brown, S. M., Napper, R. M., Thompson, C. M., \& Mercer, A. R. (2002). Stereological analysis reveals striking differences in the structural plasticity of two readily identifiable glomeruli in the antennal lobes of the adult worker honeybee. Journal of Neuroscience, 22, 85148522 .

Devoogd, T. J., Nixdorf, B., \& Nottebohm, F. (1985). Synaptogenesis and changes in synaptic morphology related to acquisition of a new behavior. Brain Research, 329, 304-308. http://dx.doi.org/10.1016/0006-8993(85)90539-6

Dyson, S. E., \& Jones, D. G. (1980). Quantitation of terminal parameters and their inter-relationships in maturing central synapses: A perspective for experimental studies. Brain Research, 183, 43-59. http://dx.doi.org/10.1016/0006-8993(80)90118-3

Ebert, B., Thorkildsen, C., Andersen, S., Christrup, L. L., \& Hjeds, H. (1998). Opioid analgesics as noncompetitive N-methyl-D-aspartate (NMDA) antagonists. Biochemical Pharmacology, 56, 553-559. http://dx.doi.org/10.1016/S0006-2952(98)00088-4

Ettenberg, A., \& Bernardi, R. E. (2007). Effects of buspirone on the immediate positive and delayed negative properties of intravenous cocaine as measured in the conditioned place preference test. Pharmacology, Biochemistry, and Behavior, 87, 171-178. http://dx.doi.org/10.1016/j.pbb.2007.04.014

Goto, Y., \& Grace, A. A. (2005). Dopamine-dependent interactions between limbic and prefrontal cortical plasticity in the nucleus accumbens: Disruption by cocaine sensitization. Neuron, 47, 255-266. http://dx.doi.org/10.1016/j.neuron.2005.06.017

Guldner, F. H., \& Ingham, C. A. (1980). Increase in postsynaptic density material in optic target neurons of the rat suprachiasmatic nucleus after bilateral enucleation. Neuroscience Letters, 17, 27-31. http://dx.doi.org/10.1016/0304-3940(80)90056-7

Harris, K. M., \& Sultan, P. (1995).Variation in the number, location and size of synaptic vesicles provides an anatomical basis for the nonuniform probability of release at hippocampal CA1 synapses. Neuropharmacology, 34, 1387-1395. http://dx.doi.org/10.1016/0028-3908(95)00142-S

Jensen, F. E., \& Harris, K. M. (1989). Preservation of neuronal ultrastructure in hippocampal slices using rapid microwave-enhanced fixation. Journal of Neuroscience Methods, 29, 217-230. http://dx.doi.org/10.1016/0165-0270(89)90146-5

Jones, D. G., \& Devon, R. M. (1978). An ultrastructural study into the effects of pentobarbitone on synaptic organization. Brain Research, 147, 47-63. http://dx.doi.org/10.1016/0006-8993(78)90771-0

Klintsova, A. Y., Goodlett, C. R., \& Greenough, W. T. (2000). Therapeutic motor training ameliorates cerebellar effects of postnatal binge alcohol. Neurotoxicology and Teratology, 22, 125-132. http://dx.doi.org/10.1016/S0892-0362(99)00052-5

Koob, G. F. (1992). Drugs of abuse: anatomy, pharmacology and function of reward pathways. Trends in Pharmacological Sciences, 13, 177-184. http://dx.doi.org/10.1016/0165-6147(92)90060-J

Mauk, M. D., Peroutka, S. J., \& Kocsis, J. D. (1988). Buspirone attenuates synaptic activation of hippocampal pyramidal cells. Journal of Neuroscience, 8, 1-11.

Morinville, A., Cahill, C. M., Esdaile, M. J., Aibak, H., Collier, B., Kieffer, B. L., \& Beaudet, A. (2003). Regulation of $\delta$-opioid receptor trafficking via $\mu$-opioid receptor stimulation: Evidence from $\mu$-opioid receptor knock-out mice. Journal of Neuroscience, 23, 4888-4898.

Moron, J. A., Abul-Husn, N. S., Rozenfeld, R., Dolios, G., Wang, R., \& Devi, L. A. (2007). Morphine administration alters the profile of hippocampal postsynaptic density-associated proteins: A proteomics study focusing on endocytic proteins. Molecular \& Cellular Proteomics, 6, 29-42. http://dx.doi.org/10.1074/mcp.M600184-MCP200

Morris, R. G., Moser, E. I., Riedel, G. Martin, S. J., Sandin, J., Day, M.,
\& O'Carroll, C. (2003). Elements of a neurobiological theory of the hippocampus: The role of activity-dependent synaptic plasticity in memory. Philosophical Transactions of the Royal Society of London, 358, 773-786. http://dx.doi.org/10.1098/rstb.2002.1264

Mucha, R. F., \& Herz, A. (1985). Motivational properties of kappa and $\mathrm{mu}$ opioid receptor agonists studied with place and taste preference conditioning. Psychopharmacology, 86, 274-280. http://dx.doi.org/10.1007/BF00432213

Riblet, L. A., Eison, A. S., Eison, M. S., Taylor, D. P., Temple, D. L., \& VanderMaelen, C. P. (1986). Neuropharmacology of buspirone. Psychopathology, 17, 69-78. http://dx.doi.org/10.1159/000284133

Safiulina, V. F., Kas'yanov, A. M., Markevich, V. A., Bogdanova, O. G., Dvorzhak, A. Y., Zosimovskii, V. A., \& Ezrokhi, V. L. (2005). Studies of the synaptic plasticity of field CA3 of the hippocampus during tetanization of the perforant path. Neuroscience and Behavioral Physiology, 35, 693-698. http://dx.doi.org/10.1007/s11055-005-0112-3

Salmanzadeh, F., Fathollahi, Y., Semnanian, S., Shafizadeh, M., \& Kazemnejad, A. (2003). Dependence on morphine leads to a prominent sharing among the different mechanisms of long-term potentiation in the CA1 region of rat hippocampus. Brain research, 963, 93-100. http://dx.doi.org/10.1016/S0006-8993(02)03947-1

Scheuermann, D. W., Krammer, H. J., Timmermans, J. P., Stach, W. Adriaensen, D., \& De Groodt-Lasseel, M. H. (1991). Fine structure of morphologically well-defined type II neurons in the enteric nervous system of the porcine small intestine revealed by immunoreactivity for calcitonin gene-related peptide. Acta Anatomica, 142, 236241. http://dx.doi.org/10.1159/000147195

Shakesby, A. C., Anwyl, R., \& Rowan, M. J. (2002). Overcoming the effects of stress on synaptic plasticity in the intact hippocampus: rapid actions of serotonergic and antidepressant agents. Journal of Neuroscience, 22, 3638-3644.

Shepherd, G. M., \& Harris, K. M. (1998). Three-dimensional structure and composition of CA3-->CA1 axons in rat hippocampal slices: Implications for presynaptic connectivity and compartmentalization. Journal of Neuroscience, 18, 8300-8310.

Sterio, D. C. (1984). The unbiased estimation of number and sizes of arbitrary particles using the disector. Journal of Microscopy, 134, 127-136. http://dx.doi.org/10.1111/j.1365-2818.1984.tb02501.x

Swift, R. M., \& Stout, R. L. (1992). The relationship between craving, anxiety, and other symptoms in opioid withdrawal. Journal of Substance Abuse, 4, 19-26. http://dx.doi.org/10.1016/0899-3289(92)90024-R

Turner, A. M., \& Greenough, W. T. (1985). Differential rearing effects on rat visual cortex synapses. I. Synaptic and neuronal density and synapses per neuron. Brain Research, 329, 195-203. http://dx.doi.org/10.1016/0006-8993(85)90525-6

Trulson, M. E., \& Arasteh, K. (1986). Buspirone decreases the activity of 5-hydroxytryptamine-containing dorsal raphe neurons in-vitro. The Journal of Pharmacy and Pharmacology, 38, 380-382. http://dx.doi.org/10.1111/j.2042-7158.1986.tb04591.x

Weibel, E. R., Kistler, G. S., \& Scherle, W. F. (1966). Practical stereological methods for morphometric cytology. The Journal of Cell Biology, 30, 23-38. http://dx.doi.org/10.1083/jcb.30.1.23

Withers, G. S., Fahrbach, S. E., \& Robinson, S. E. (1993). Selective neuroanatomical plasticity and division of labour in the honeybee. Nature, 364, 238-240. http://dx.doi.org/10.1038/364238a0

Yocca, F. D. (1990). Neurochemistry and neurophysiology of buspirone and gepirone: Interactions at presynaptic and postsynaptic 5HT1A receptors. Journal of clinical psychopharmacology, 10, 6S12S. http://dx.doi.org/10.1097/00004714-199006001-00003

Yuan, X. R., Madamba, S., \& Siggins, G. R. (1992). Opioid peptides reduce synaptic transmission in the nucleus accumbens. Neuroscience Letters, 134, 223-228. http://dx.doi.org/10.1016/0304-3940(92)90522-9

Zhang, Z., \& Schulteis, G. (2008). Withdrawal from acute morphine dependence is accompanied by increased anxiety-like behavior in the elevated plus maze. Pharmacology, Biochemistry, and Behavior, 89, 392-403. http://dx.doi.org/10.1016/j.pbb.2008.01.013 